\title{
LOBOTOMIA PRÉ-FRONTAL
}

\section{ANTONIO CARLOS BARRETTO *}

Não considerando as lendárias trepanações dos Incas peruanos com a finalidade de curar as doenças mentais, teríamos o início da psicocirurgia nas exereses corticais múltiplas e unilaterais de Burckhardt ${ }^{1}$, nas secções subcorticais interrompendo as fibras de associação entre o lobo frontal de Puussepp ${ }^{2}$, nas lobectomias unilaterais de Ody ${ }^{3}$. Entretanto, foi sòmente com a leucotomia de Egas Moniz ${ }^{4}$, destruindo conexões de grupos celulares do lobo pré-frontal, responsáveis por certos estados psíquicos mórbidos, que a psicocirurgia tomou grande impulso. Todavia, foi Freeman ${ }^{5}$ o generalizador desta nova modalidade cirúrgica. Considerando a intervenção de Muniz pouco ampla, propôs Freeman a lobotomia pré-frontal, com a secção das fibras tálamo-frontais. Pondo em prática uma técnica rigorosa, Freeman e seu colaborador Watts delinearam as etapas pré e pós-operatórias, precisaram as indicações e abordaram os problemas fisiopatológicos. A desorientação e apatia em que caem os doentes, à medida que os lobos pré-frontais são seccionados, mostram o valor e precisão da intervenção. A lobotomia pré-frontal é a última aquisição no campo da psicocirurgia e, também, a mais exata e controlável. Muitas são as técnicas empregadas, defendendo cada autor o seu ponto de vista. Não iremos criticá-las, mas sòmente fazer breve resumo sôbre os vários processos, relatando, ao mesmo tempo, nossa experiência e as modificações que introduzimos, de acôrdo com as possibilidades de nosso meio cirúrgico hospitalar.

Em regra, não levamos em grande conta o estado geral do paciente; muitos doentes em mau estado geral melhoraram sensivelmente com a

Trabalho entregue para publicação em 20 setembro 1945.

* Cirurgião do Hospital de Juqueri (S. Paulo).

1. Burckhardt, G. - Ueber Rindenexcisionen, als Beitrag zur operativen Therapie der Psychosen. Allg. Ztschr. f. Psychiat. 47:463, 1890-1891.

2. Puussepp, L. - Alcune considerazioni sugli interventi chirurgici nelle malatie mentali. Giorn. R. Accad. Torino, 100:3, 1937.

3. Ody, F. - Le traitement de la démence précoce par ressection du lóbe pré-frontal. Arch. Ital. di Chir, 53:321, 1938.

4. Moniz, E. - Tentatives operatoires dans le traitement de certaines psychoses. Masson et Cie., Paris, 1936.

5. Freemann, W. e Watts, J. - Psychosurgery. Charles C. Thomas Publisher, Springfield, Illinois, 1942. 
intervenção. $\mathrm{O}$ problema da idade também é posto à margem: já operamos doentes com mais de 60 anos, sem complicações secundárias. Quanto ao anestésico, continuamos a usar, como já o fazíamos na leucotomia pré-frontal a Moniz ${ }^{6}$, o Scophedal como anestésico de base nos agitados; administramos sistemàticamente $0,20 \mathrm{gr}$. de Luminal na véspera e $0,10 \mathrm{gr}$. pouco antes da intervenção. Pesquisamos sempre o tempo de sangria e coagulação. Quando queremos a localização radiológica dos planos de seç̧ão em relação aos ventriculos, fazemos, minutos antes do doente ir para a sala cirúrgica, a pneumencefalografia por punção suboccipital. O paciente vai para a sala operatória, tendo já a cabeça raspada na sua metade anterior e a região a trepanar marcada com corante. Os cabelos da parte posterior da cabeça são isolados com esparadrapo. $\mathrm{Na}$ mesa cirúrgica, o doente permanece em decúbito dorsal. Assepsia com iodo-álcool. Anestesia local por infiltração de $10 \mathrm{cc}$. de novocaína a $1 \%$ em cada região a ser incisada. Os tempos que seguem variam um pouco, conforme a técnica empregada.
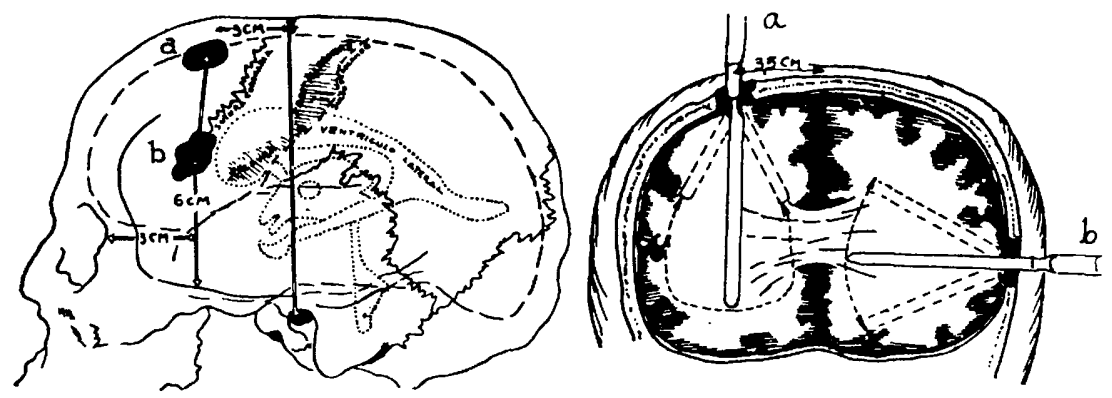

FIG. 1 - Em a, trepanação e plano de secção segundo F.gas Moniz; em $b$, segundo Freenian-Watts.

Operamos os primeiros doentes usando as reterências de Moniz; na região frontal, a $3,5 \mathrm{~cm}$. da linha mediana, sôbre outra, frontooccipital a $3 \mathrm{~cm}$. adiante do tragus (fig. 1). Incisão do couro cabeludo e periósteo, sendo êste ruginado. A hemostasia é feita por compressão, pelo afastador auto-estático. O ôsso é trepanado com o aparêlho elétrico de De Martel, sendo a abertura óssea tamponada com gaze; enquanto se espera que a pequena hemorragia cesse, o lado oposto é também trepanado e tamponado. Voltando à primeira trepanação, o tampão de gaze é retirado, assim como a lâmina vítrea; a dura-meninge é exposta e incisada crucialmente em zona avascular e a pia-meninge perfurada, após ampliação da abertura óssea com saca-bocados. Reputa-

6. Barretto, A. C. - Leucotomia pré-frontal à Egas Moniz. Arq. NeuroPsiquiat. (São Paulo) 2:248-254 (setembro) 1944. 
mos de grande importância os pontos de referência intracerebrais; introduzimos primeiramente o trocáter em direção ao globo ocular e, a mais ou menos, $6,50 \mathrm{~cm}$. de profundidade, encontramos um plano ósseo, representado pelo teto da órbita ou asa do esfenóide. Com esta inclinação, deveremos razar o polo anterior do ventrículo lateral. Âs vezes, o ventrículo é atingido quando a inclinação do trocáter é pequena; neste caso, o instrumento é retirado e novamente introduzido com inclinação maior. Introduzindo, depois, o trocáter em direção medial, percebe-se a resistência da foice do cérebro. Localizados êstes pontos de referência, o lobótomo (descolador de periósteo de Killiam) é introduzido no mesmo plano, com a profundidade de $1 \mathrm{~cm}$. a menos; com manobras lentas para a esquerda e para a direita, seccionamos a substância branca em maior ou menor quantidade (fig. 1). A mesma intervenção é realizada do lado oposto. A sutura do couro cabeludo é feita em plano único, com fio de algodão contínuo ou em pontos separados.

Crombie usa aparêlho especial cuja lâmina de secção tem $3 \mathrm{~cm}$. de diâmetro. Faz a trepanação a $3 \mathrm{~cm}$. para trás do bordo lateral da órbita e a $5 \mathrm{~cm}$. acima da arcada zigomática. Baseados no aparêlho daquele autor, mandamos construir um semelhante, que proporciona os mesmos resultados. Estes aparelhos são de manêjo fácil e permitem precisão nos cortes. Seccionamos junto ao polo anterior do ventrículo uma circunferência de $3 \mathrm{~cm}$. de diâmetro, o que representa a quase totalidade das fibras brancas que por aí passam. A substância cinzenta é poupada ao máximo.

Lyerly faz a lobotomia usando uma trepanação ampla: põe a descoberto a região frontal, incisa a segunda circunvolıção frontal em sua parte média e, a céu aberto, corta a substância branca subjacente.

A região preconizada por Freeman e Watts para a trepanação está situada verticalmente a $6 \mathrm{~cm}$. acima da arcada zigomática e, posteriormente, a $3 \mathrm{~cm}$. do bordo lateral da órbita (fig. 1). Atualmente temos usado sòmente esta via que dá mais campo operatório e mais precisão na secção das fibras. Depois do preparo do doente e marcados os pontos de referência, é feita uma incisão vertical de $3 \mathrm{~cm}$. atingindo couro cabeludo, músculo temporal e periósteo. O afastador auto-estático susta por compressão a hemorragia, ao mesmo tempo que afasta o couro cabeludo e músculo. Com rugina, o periósteo é afastado, deixando descoberta a sutura coronária. Após a trepanação, um tampão de gaze contém a pequena hemorragia óssea. A mesma intervenção é realizada do lado oposto. Hemorragias ósseas mais rebeldes são cuidadas com tamponamento com água oxigenada, ou com fibras maceradas do músculo temporal. Com saca-bocados, amplia-se no sentido da sutura coronária o orifício ósseo. A dura-meninge é aberta crucialmente em zona avascular. A pia-meninge é perfurada. Um trocáter inserido no cérebro, com a ponta orientada para o buraco do lado oposto, deverá pas- 
sar adiante do polo anterior do ventrículo lateral e atingir a foice do cérebro a 5,5 ou $6 \mathrm{cms}$. Um pequeno desvio para trás levará ao joelho do corpo caloso ou ao ventrículo. Reconhece-se que o corpo caloso foi atingido quando o trocáter, caminhando fàcilmente a $6 \mathrm{~cm}$., não encontra resistência da foice ou o ventrículo. Quando isto acontece, o trocáter é retirado e orientado mais para a frente. Identificada a foice do cérebro, o instrumento é retirado e dirigido para baixo, com uma inclinação de $45^{\circ}$, sempre no plano da sutura coronária; a 4 ou $5 \mathrm{cms}$. de profundidade é encontrado um plano resistente, representado pela asa do esfenóide. Localizados êstes pontos, o trocáter é substituído pelo lobótomo que, ao encontrar a resistência da foice do cérebro, é recuado de $0,5 \mathrm{~cm}$. para se afastar dos vasos aí localizados. Delicada e vagarosamente, faz-se a seç̧ão da substância branca, no plano da sutura coronária. Qualquer resistência percebida durante a secção da parte inferior ou superior junto ao polo do ventrículo deverá ser evitada. Nestes casos, o lobótomo é retirado e recolocado novamente para a frente da resistência notada; com esta manobra, evitaremos a secção de um vaso de grande calibre. Os mesmos tempos cirúrgicos são realizados no lado oposto. Finda a lobotomia, injetávamos, com agulha de punção lombar, lipiodol ou neo-iodipina no plano da secção (fig. 2).

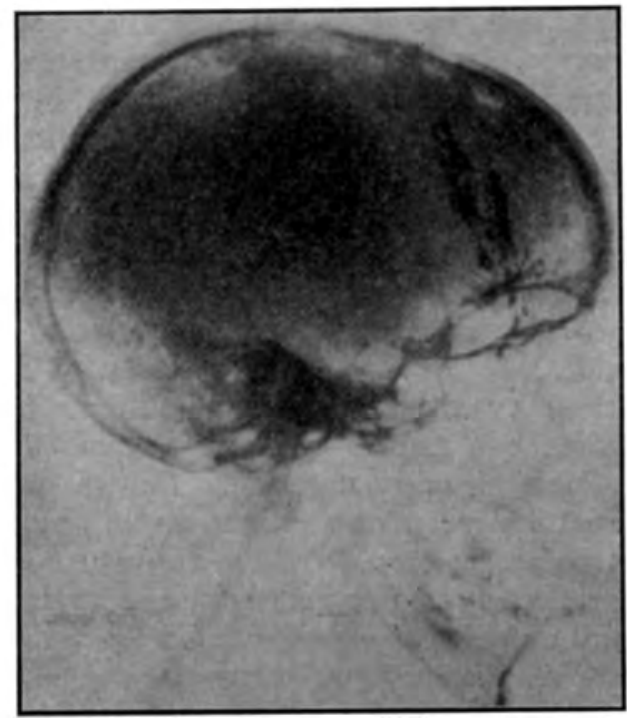

FIG. 2 - Radiografia com lipiodol no plano de seç̧ão da lobotomia.

Idealizanos um pequeno lobótomo que simplifica muito a intervenção (fig. 3). E' um instrumento achatado e não cortante como o des- 


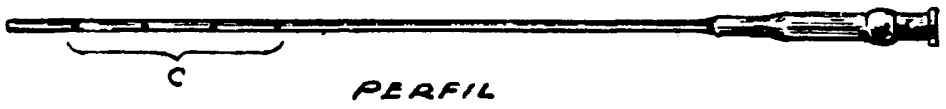

PEAFIL

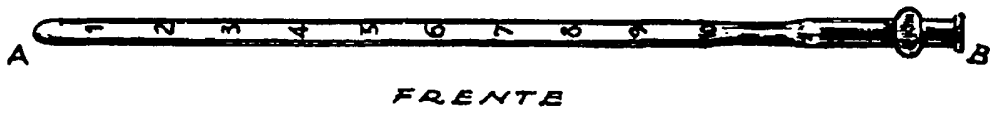

FIG. 3 - Aparêlho idealizado pelo autor para servir ao mesmo tempo de catéter, lobótomo e para a injeção de lipiodol.

colador de Killiam, sendo porém ôco como uma agulha e tendo vários pertuitos em um dos bordos. Uma das extremidades é romba e fechada, e a outra aberta com dispositivo para adaptar uma seringa. Com êste lobótomo, dispensamos o trocáter e a agulha; êle serve para localizar os pontos de referência e, sendo furado, o líquor drenará fàcilmente se o ventrículo fôr atingido. Identificada a foice do cérebro e a asa do esfenóide, a secção da substância branca é feita lentamente para cima e para baixo do polo ventricular, sempre no plano coronário. Feita a lobotomia, sem retirar o aparêlho, adaptamos uma seringa com lipiodol ou neo-iodipina e injetamos lentamente, à medida que fazemos o lobótomo percorrer o plano já seccionado e, portanto, sem resistência alguma. A radiografia mostrará, depois, o plano de secção contrastado.

Para melhor localizar os pontos de referência, temos usado, com resultados técnicos apreciáveis, um longo estilete de $20 \times 0,5 \mathrm{~cm}$. que atravessa o lobo pré-frontal de um lado a outro, pelos orifícios de trepanação. Precisando as referências, saberemos onde e quanto do centro oval poderemos seccionar. Para transfixar o lobo frontal pelo estilete, fazêmo-lo penetrar em um dos orifícios de trepanação, orientando-r em direção ao buraco do lado oposto. A mais ou menos $5 \mathrm{~cm}$. de profundidade, encontraremos a resistência representada pela foice; esta é vencida pela transfixação e o estilete continua a caminhar em direção ao lado oposto, até atingir na outra abertura. Deverá passar um pouco adiante do polo ventricular; com o estilete assim fixo nas duas aberturas, teremos os polos frontais divididos em quatro quadrantes, dois superiores e dois inferiores. Seccionaremos os quatro quadrantes ou sòmente os dois inferiores, correspondentes à zona orbitária do lobo frontal. Hofstatter e colaboradores ${ }^{7}$ afirmam que os efeitos benéficos da terapêutica cirúrgica são nítidos quando seccionados sòmente os quadrantes inferiores. Desempenhariam as áreas orbitárias, segundo êstes

7. Hofstatter, L., Smolik, E. A. e Busch, A. K. - Prefrontal lobotomy in treatment of chronic psychoses, with special reference to section of the orbital areas only. Arch. Neurol. a. Psychiat. 53:125-130 (fevereiro) 1945. 
autores, um papel de regulador das emoções; os resultados que obtiveram são satisfatórios.

Os pontos de reparo do crânio, preconizados por Moniz, Crombrie, Freeman e Watts, embora bons, não dão sinão relativa precisão sôbre a situação dos polos anteriores dos ventrículos laterais, que são as referências mais visadas. Temos verificado que, em alguns casos, apesar da tomada das medidas externas em crânios bem conformados, os ventrículos são atingidos ao ser procurada a foice do cérebro. O ideal seria, como já dissemos, fazer sistemàticamente, antes da lobotomia, a fneumencefalografia; desta maneira, mesmo com um ventrículo anormalmente situado, não correremos o risco de atingí-lo. A lobotomia pré-frontal passará a ser, então, a intervenção psicocirúrgica mais exata e controlável. Já temos realizado várias lobotomias precedidas de pneumencéfalo, sem maiores complicações. Com a sistematização que temos usado, a lobotomia pré-frontal passa a ser uma intervenção relativamente fácil, dispensando perfeitamente o aparato das outras operações neurocirúrgicas e podendo ser realizada sem a ajuda de assistentes.

Realizamos, até o presente, 42 lobotomias, sem registrar morte ou qualquer acidente grave durante o ato cirúrgico ou no pós-operatório. Conversando com o doente, durante o ato operatório, nota-se que suas idéias se tornam confusas à medida que são seccionadas as fibras tálamo-frontais e que a confusão atinge a máximo após a secção do quarto e último quadrante. Apesar disto. o paciente sai da mesa cirúrgica locomovendo-se bem, voltando para a enfermaria sem ajuda da enfermagem. Seis horas após a intervenção recebe alimento leve. Dentre as alterações psíquicas, a apatia, o torpor e, mais raramente, a euforia são os que chamam a atenção. As perturbações gerais e neurológicas são de pouca monta e passageiras; hipertermia ligeira $\left(37^{\circ}, 5 \mathrm{C}\right.$ em média), vômitos e, algumas vezes, certo relaxamento temporário dos esfincteres. Do terceiro dia em diante o paciente já se levanta e, no $5 .^{\circ}$ ou $6 .^{\circ}$ dia, são retirados os pensos. Desde os primeiros dias deve ser iniciada a reeducação psíquica.

Iniciamos as lobotomias em outubro de 1943. Não obtivemos, em nossos operados, os brilhantes resultados referidos por Freeman e Watts, provàvelmente em conseqüência do péssimo material que pudemos utilizar, todo êle constituído de casos crônicos, considerados incuráveis, já submetidos a outros tratamentos psiquiátricos tais como insulina, cardiozol e eletrochoque e, mesmo. já operados pela técnica de Moniz, sem resultado algum. Acresce ainda o índice cultural nulo da maioria dos doentes e a dificuldade de reeducação no pós-operatório. Só recentemente é que iniciamos a lobotomia pré-frontal como primeira intervenção psicocirúrgica, não podendo apresentar ainda os resultados estatísticos, pelo pouco tempo de observação. Relataremos apenas uma de nossas últimas observações, na qual se evidencia claramente o efeito 
benéfico da lobotomia frontal. Servirá o caso também para mostrar que uma operação anterior sem resultado não deve levar ao abandono do caso ; uma segunda e mesmo terceira intervenção deve ser tentada.

Tratava-se de Maria C., com 25 anos, casada, branca, brasileira. Início da moléstia em março de 1943. Internada em junho de 1943 com o diagnóstico de síndrome esquizofrênica, forma hebefrênica (Dr. Edmundo Maia). Foi submetida a 30 crises cardiazólicas até fevereiro de 1944, sendo considerada como não influenciada. O caso foi revisto em março pelo Dr. Mario Yahn: a estrutura esquizofrênica continuava inalterada; a doente era apática e de facies indiferente; às vezes, ria de maneira infantil e o pensamento não era ordenado segundo uma certa tensão psicológica originada num fim a ser atingido. Foi proposta a insulinoterapia, sendo submetida a 28 comas até abril de 1944, quando foi reexaminada, sendo considerada ainda como não influenciada. Foi proposta a leucotomia de Egas Moniz, apesar do prognóstico ser mau. Operada em 12 maio 1944, pela técnica de Moniz, foram feitos 5 cortes em cada lobo pré-frontal. Em 12 junho 1944, continuava apática, desinteressada e alheada; respostas sem colorido afetivo, riso fácil e atoleimada. Foi indicada, então, a lobotomia pré-frontal, intervenção realizada em 20 outubro 1944, usando as referências cranianas de Moniz. Nenhum acidente operatório. Pós-operatório normal. Pouco tempo após a intervenção, começou a apresentar sensíveis melhoras; voltou a auxiliar nos serviços da enfermaria, interessou-se pela sua alta. A família, notando as melhoras, levou-a com licença de prova em novembro de 1944. Após 4 meses, o marido pedia alta definitiva, posto que a julgava totalmente normal, informando que ao chegar em casa logo se mostrou alegre e disposta, passando a ocupar-se dos afazeres com grande proficiência. Nesse estado de remissão completa a doente se conserva até agora.

RESUMO

O A., cirurgião do Hospital de Juqueri (S. Paulo), comenta as várias técnicas da lobotomia pré-frontal, especialmente a de FreemanWatts.

Faz referências a um lobótomo por êle idealizado, que consta de um trocáter achatado. Esste aparêlho é utilizado não só para a sondagem dos pontos de reparo e secção das fibras, como para depositar lipiodol no plano seccionado.

Com a finalidade de precisar melhor os pontos de referência, tem usado, também, um estilete que transfixa os dois polos frontais, perfurando a foice do cérebro, através dos orifícios de trepanação. Aconselha também que se faça sistemàticamente, antes da intervenção, a pneumencefalografia, com a finalidade de localizar a posição dos ventrículos. Apresenta sòmente os resultados parciais dos seus operados (42), em vista do pouco tempo decorrido da intervenção. Descreve a observação de uma doente que obtivera remissão completa pela lobotomia, depois de ter já sido submetida ao tratamento pelo cardiazol, insulina e leucotomia de Egas Moniz.

Todos os pacientes operados eram crônicos, nos quais todos os outros recursos terapêuticos, inclusive a leucotomia de Egas Moniz, tinham falhado. Não teve caso algum de morte ou acidente grave, durante o ato cirúrgico ou no pós-operatório imediato. 


\section{SUMMARY}

The foregoing paper deals with the author's experience as a surgeon at Juqueri State Hospital (S. Paulo, Brazil), working in neurosurgery. Several techniques for lobotomy are discussed, especially Freeman-Watts'.

The writer devised a lobotome for a three-fold purpose, viz. to ascertain the reference marks, severe the fibers and leave iodine-oil in transection track. The instrument consists of a trocar slightly flatened to take the shape of a regular leukotome and having one of the ends sealed. In one of the severing edges near the blind end there are four small holes, one $\mathrm{cm}$. apart from each other. Through the free end a syringe may easily draw liquor and inject the contrast into the transection surface.

To secure a better placing of the transection, the writer has recently followed the technique of transfixing the falx and both frontal poles with a stylet inserted through the burr holes. He also recommends to have a pneumoiencephalography sistematically performed before operation in order that the ventricles be readily localized. Therapeutic results are presented only in part, regarding this lobotomy series of 42 mental patients. The author felt the postoperative time was not long enough to allow a correct follow-up. One of the patients (a female, 25 years old) already showed a full recovery credited to lobotomy since it was performed only after the metrazol treatment, the insuline series and even the leukotomy after Moniz have all failed.

All of the patients operated upon were chronic cases who had undergone all of the accepted therapies including Egas Moniz' psychosurgery. No casualty or severe accident was met with during operative procedure and immediate postoperative period.

Rua Conselheiro Moreira de Barros, 649 - S. Paulo 